\title{
Certification and integration of management systems: the experience of Portuguese small and medium enterprises
}

\author{
Gilberto Santos $^{\mathrm{a}, *}$, Fátima Mendes ${ }^{\mathrm{b}}$, Joaquim Barbosa ${ }^{\mathrm{c}}$ \\ ${ }^{a}$ Escola Superior de Tecnologia, Polytechnic Cavado e Ave, Barcelos, Portugal \\ ${ }^{\mathrm{b}}$ Former Master Student, University of Minho, Guimarães, Portugal \\ ${ }^{\mathrm{c}}$ University of Minho, Guimarães, Portugal
}

\section{A R T I C L E I N F O}

Article history:

Received 12 February 2010

Received in revised form

7 June 2011

Accepted 23 June 2011

Available online 30 June 2011

\section{Keywords:}

Quality management systems

Environmental management systems

Occupational health and safety

management system

Integrated management systems

\begin{abstract}
A B S T R A C T
The purpose of this study was to characterize the situation of Portuguese Small and Medium Enterprises (SMEs) concerning the certification of their Quality Management Systems (QMS), Environmental Management Systems (EMS) and Occupational Health and Safety Management Systems (OHSMS), in their individually form, to identify benefits, drawbacks and difficulties associated with the certification process and to characterize the level of integration that has been achieved. This research was based on a survey carried out by the research team; it was administered to 46 Portuguese SMEs. Our sample comprised 20 firms (43\%) from the Trade/Services activity sector, 17 (37\%) from the Industrial sector, 5 (11\%) from the Electricity/Telecommunications sector and 4 (9\%) from the Construction area. All SMEs surveyed were certified according to the ISO 9001 (100\%), a quarter of firms were certified according to the ISO 14001 (26.1\%) and a few certified by OHSAS 18001 (15.2\%). We undertook a multivariate cluster analysis, which enabled grouping variables into homogeneous groups or one or more common characteristics of the SMEs participating in the study. Results show that the main benefits that Portuguese SMEs have gained from the referred certifications have been, among others, an improvement of both their internal organization and external image. We also present the main difficulties in achieving certification. Overall, 7 of the Portuguese SMEs examined indicated that the main benefits of the IMS implementation management included costs reduction, increased employee training and easier compliance of legislation. The respective drawbacks and difficulties are also presented. Finally, we presented the main integrated items in the certified Portuguese SMEs we examined.
\end{abstract}

(c) 2011 Elsevier Ltd. All rights reserved.

\section{Introduction}

Certification of products and processes began during the 1960's in the manufacturing industry, as a tool to control and assure the quality/conformity of products and services provided by suppliers to customers/consumers (Wright, 2000). At first the implementation of a Quality Management System (QMS) was particularly relevant in high demanding activity sectors, like the automotive and aeronautical industries, but it has rapidly extended to every activity sector, becoming a common requisite of any company worldwide and a factor of competitiveness and survival.

Due to the increasingly demanding environmental legislation in developed countries, companies nowadays are required to seriously take into consideration not only environmental aspects associated to the production chain itself, but also to the life cycle of

\footnotetext{
* Corresponding author. Tel.: +351 253802260; fax: +351 253823127

E-mail address: gsantos@ipca.pt (G. Santos).
}

their products. They are forced to implement suitable Environmental Management Systems (EMS) to reduce wastes and to protect environment. This is a particularly important issue for small and medium-sized companies (SMEs), which are considered to make up the vast majority of business in Europe (Zorpas, 2010). They are quoted as contributing $70 \%$ of global environmental pollution, with the majority coming from the manufacturing sector (Burke and Gaughran, 2007).

Moreover, creating and maintaining a safe working environment ensures that workers have high health levels, protecting them from accidents, illness or discomfort in the workplace and increases the efficiency of work processes, improves employee perceptions of their working environment and leads to higher recruitment attractiveness (Tsai and Chou, 2009). Such aspects generate obvious benefits for entrepreneurs and employees, increasing a company's competitiveness while decreasing social costs. To achieve such a goal, companies are now implementing Occupational Health and Safety Management Systems (OHSMS), creating sustainable competitive advantages. 
Thus, the implementation and management of all economical, environmental and social aspects within a company is gradually becoming a crucial requirement for any business and has become a widespread phenomenon around the world (Zeng et al., 2007). Large companies are increasingly requiring this management policy from their suppliers, establishing specific requests and performances that SMEs often find extremely difficult to accomplish.

The certification of such Management Systems requires accomplishing specific standards and being submitted to periodical audits, namely ISO 9001 standards for Quality Management Systems (QMS), ISO 14001standards for Environmental Management Systems (EMS) and OHSAS 18001 standards for Occupational Health and Safety Management Systems (OHSMS). Nevertheless, implementation and management of these three systems in parallel demands many duplicate management tasks and requires different human resources, making it difficult to operate these and to ensure their alignment with the organization strategy (Zeng et al., 2007).

These three standards contain the same basic principles and a general common structure (Fresner and Engelhardt, 2004; Block and Marash, 2002). They all require the definition of roles and responsibilities, to train personnel, to define written procedures, to control and keep records of documentation and data, to continuously improve by applying "root cause" analysis to corrective and preventive action, to perform internal audits, and so on (Wright, 2000; Zeng et al., 2007). Thus, it is of great interest to integrate them, which can be done at different levels (Jørgensen et al., 2006). Management systems integration is a way forward, and standard ISO 19011 (to guide environment and quality joint audits) is a good example of that. Moreover, a single integrated management system coordinated by a multidisciplinary team, thereby saving both financial and human resources is a key issue for the future (Santos et al., 2008; Mendes, 2007). Combining all three Management Systems in order to implement a single Integrated Management System (IMS) is considered to promote significant cost reduction (in external audits, for example) which will depend on the size of the organization and the nature of its activity (Wright, 2000). Moreover, integration is considered to have a beneficial effect on the culture of the organization, in that it promotes less departmental 'isolation', and more of a team ethic between the various functions (Wright, 2000). A changing culture is dawning, one that is paving the way from Total Quality (TQ) to Integrated Total Quality (ITQ). In recent years the standards for management systems have become more compatible, and organizations may need support to understand the common principles and approaches to IMS. The number of companies with more than one certification is rising steadily and many of them are already experimenting with integration. For this reason, several countries, such as New Zealand, Australia, France, the Netherlands, Denmark and Spain, have developed or are developing their own "IMS standard" (Jørgensen et al., 2006; Salomone, 2008).

During the last years many researchers from different countries have focused their attention on this subject, having studied and evaluated the possibility of integrating quality, environmental and health and safety management systems, identifying their benefits and drawbacks for organizations, characterizing the level of integration in organizations that operate in different activity fields and with different sizes, and so on. In Spain, for example, an empirical study revealed that although full integration of all aspects of the implemented Management Systems has not been achieved yet, a very large number of companies ( $87 \%$ of 362 companies) have a great part of their Management Systems already integrated (Bernardo et al., 2009). The policy, objectives and manual were found to be the most integrated goals and documentation resources, while document and record control, internal audits and communication are the most integrated procedures. In this study, researchers also concluded that organizations follow similar integration patterns, starting with the most strategic goals, documentation and procedures, integrating operations and tactics on a later stage. Moreover, no matter the level of integration, the responsibility for the different Management Systems often falls on the same person, but, in some cases, different people may manage an Integrated System. Another study by the same researchers revealed that internal and external audits are integrated to some degree or for some components or aspects, regardless of whether or not the implemented Management Systems are themselves integrated (Bernardo et al., 2010). This pattern is in line with the findings of other researchers, such as Karapetrovic and Casadesús (2009), confirming that organizations prefer the integration of management system audits to managing and conducting them separately. Similar studies carried out in China by Zeng et al. (2007) revealed that 61 out of 104 companies surveyed had implemented Integrated Management Systems to avoid several drawbacks associated to parallel Management System; these are the same drawbacks referred by Bernardo et al. (2009); Karapetrovic and Casadesús (2009).

Recently, the management of Health, Safety and Environment (HSE) Systems has become a key issue in most European countries, where legislation on this matter has become extremely demanding for industrial companies. A study carried out by Duijm et al. (2008) in several EU countries (Denmark, Greece, France, Slovenia, Poland, Belgium and Germany) revealed that industry considers HSE management systems are becoming increasingly complex and bureaucratic, and a strong effort should be done to make them simple. The way HSE systems are integrated depends on the size of the companies. Large companies usually run integrated management systems that include HSE while medium-sized companies prefer to run individual systems, usually identified with personal skills, due to the administrative complexity of implementing integrated HSE. In small companies, integration takes place naturally, and a single person is responsible for its management, often covering concurrent tasks, which can make it difficult to identify priorities. Although significant differences were found in national legislation between EU member states, EU industry tends to complain about the large number of required audits and inspections, and demands an improvement on its efficiency. Although most EU companies consider that HSE systems contribute to increased profitability and to environment protection, in some countries, like Lithuania, HSE systems implementation is still driven by economic benefits rather than by "green idealism" (Staniskis and Stasiskiene, 2006).

The Portuguese industry consists mainly of Small and Medium Enterprises (SMEs), where activity and performance are crucial factors for the country's development. SMEs make up 75\% of the total labor force employed in industry, trade and services. According to the Ministry of Economy and Innovation's website (http://www.min-economia.pt/2007) SMEs are responsible for $99.5 \%$ of national business, generating $74.7 \%$ of employment; furthermore, SMEs held $59.8 \%$ of sales nationwide. They are the bedrock of the Portuguese economy. A good example of Management Systems Certification and Integration in Portugal is represented in Fig. 1. For a long time, the only foundry in the country to have its Quality, Environment and Health and Safety systems certified was Kupper and Schmidt, an SME that supplies exclusively the automotive industry and exports about $98 \%$ of its production to European and American markets. Just a few years after starting its activity, the company had its Quality System already certified by the main customers. In 1997 it was certified according to ISO 9002 standard, in 1998 by QS-9000, in 1999 by VDA 6.1, and in 2001 by ISO/TS 16949 standards. In 2000 the company focused on the environment, and obtained the certification according to ISO 14001 standard. Since 2002 the company has had its Health and Safety System certified according to OHSAS 18001 (Santos et al., 2004). Presently, the company runs an 


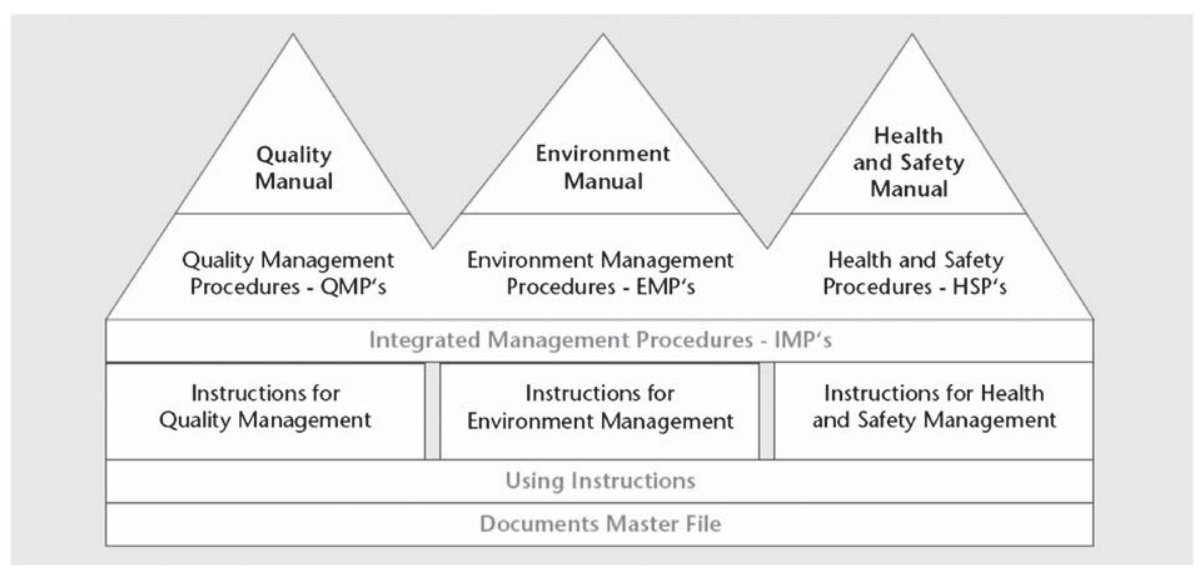

Fig. 1. Documental structure of the Integrated Management Systems at Kupper \& Schmidt.

Integrated Management System regarding management procedures, operating instructions and documentation.

The objective of this study is to characterize the present situation of Portuguese SMEs in this field, namely to identify difficulties associated with the certification process, to highlight the main benefits and drawbacks that arise from certification and, to characterize the level of integration that has been achieved.

\section{Methodology}

In the last years there has been a significant increase in the number of Portuguese companies certified in Quality, Environment and Health and Safety. However, the impact of certification in the companies' management and performance, the certification models/routes that have been followed. It's degree of integration of such systems are not known.

In order to characterize the Portuguese industry, a survey based on a questionnaire was carried out in several Portuguese SMEs. Such a tool enables researchers to gather a great amount of information at a low cost, regardless of the significant non-response usually associated to surveys.

In the first stage the questionnaire was validated by carrying out a pre-test in six companies of different activity sectors; these firms had implemented at least one certification system. The main goals of this first stage were to identify possible difficulties with the interpretation of the questionnaire and to eliminate or reformulate questions that were unanswerable. The questionnaire was sent via e-mail or delivered personally in hand, explaining and justifying its main objectives. Based on the results of this pre-test, some questions were removed and others were rewritten, according to suggestions made by some companies that participated in the pretest.

The final questionnaire was organized in five sections, according to Table 1. Both qualitative and quantitative answers were asked, depending on the nature of the question and the available data. Beyond the questionnaire's main topics presented in Table 1, one last question was included: Would the company prefer one single standard for the certification of every management system? Companies were requested to justify their answer to this question, regardless of the answer provided.

The questionnaire was sent by e-mail to 300 SMEs with a certified quality management system, along with a cover letter describing the objectives of the research and instructions on how to fill out the survey. 162 companies were located in the center region of Portugal (including the Lisbon area), 114 in the northern region (including the Oporto area) and 24 in regions located south of
Lisbon. According to the data available from the "SMEs Portugal Association" this distribution is proportional to the location of SMEs within Portugal. (htpp://www.pme.online.pt/2007).

80 companies answered the survery, but only 46 had been validated, thus representing the sample size of the Portuguese territory. Of those 46 companies, 20 (43\%) were from the Trade/ Services activity sector, 17 (37\%) from the Industrial sector, 5 (11\%) from the Electricity/Telecommunications sector and 4 (9\%) from the Construction area (Fig. 2).

Once the information had been collected, the next step consisted of the analysis and interpretation of data. An Excel file had been created with the collected data, and then exported to SPSS (Statistical Package for Social Sciences). SPSS is a powerful software

Table 1

Main sections and question main topics of the questionnaire.

\begin{tabular}{|c|c|}
\hline Main Sections & Questionnaire main topics \\
\hline $\begin{array}{l}\text { General Description of } \\
\text { the Company }\end{array}$ & $\begin{array}{l}\text { Number of employees; Volume of business; Branch of } \\
\text { activity; Main products and markets; etc. }\end{array}$ \\
\hline \multirow[t]{7}{*}{ Quality System } & Year of ISO 9001 certification; \\
\hline & Main reasons for Quality certification; \\
\hline & Main difficulties; \\
\hline & Main benefits that arose from certification (new \\
\hline & $\begin{array}{l}\text { costumers, image, competitiveness, business increase, } \\
\text { quality improvement, customer satisfaction, products } \\
\text { innovation, organization improvements, etc.); }\end{array}$ \\
\hline & Main drawbacks; \\
\hline & Quality tools that the company uses; \\
\hline \multirow[t]{6}{*}{ Environmental System } & Year of ISO 14001 certification; \\
\hline & Main reasons for Environmental certification; \\
\hline & Main difficulties; \\
\hline & Main benefits that arose from certification (waste \\
\hline & $\begin{array}{l}\text { reduction, waste destination, environmental costs } \\
\text { reduction, etc); }\end{array}$ \\
\hline & Main drawbacks; \\
\hline \multirow{5}{*}{$\begin{array}{l}\text { Health and Safety } \\
\text { System }\end{array}$} & Year of OHSAS 14001 certification; \\
\hline & Main reasons for Health and Safety certification; \\
\hline & Main difficulties; \\
\hline & $\begin{array}{l}\text { Main benefits that arose from certification (reduction } \\
\text { of the number of accidents, productivity increase, } \\
\text { absenteeism, etc); }\end{array}$ \\
\hline & Main drawbacks; \\
\hline \multirow[t]{5}{*}{ Systems Management } & Running independently or integrated; \\
\hline & $\begin{array}{l}\text { Degree of integration (integrated systems, what is } \\
\text { integrated, reasons for integration, management } \\
\text { structure, etc); }\end{array}$ \\
\hline & $\begin{array}{l}\text { Main benefits of integration (cost reduction, } \\
\text { management simplification, etc); }\end{array}$ \\
\hline & Main difficulties; \\
\hline & Main drawbacks: \\
\hline
\end{tabular}




\section{Companies by sector}

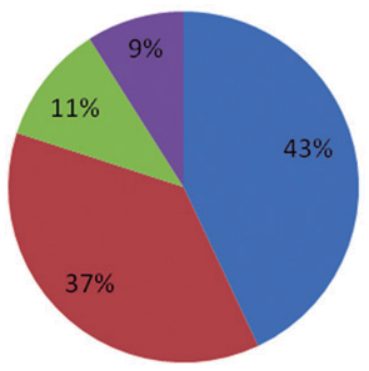

Trade/Services

Industrial Sector

Electricity/

telecommunications

- Construction Área

Fig. 2. Distribution of participating companies by sector of activity.

to support statistics, which provides complex statistical calculations; however, due to the small sample size, two obstacles arose: understanding what statistical test to use and how to interpret the results correctly. Thus:

1. Statistical techniques - It was used primarily for inductive and descriptive statistics: average, frequency plots, the principal component analysis, cluster analysis and statistical inference to find important conclusions about the population inferred from analysis of the sample, bearing in mind that small sample size is a limitation.

2. Kaiser-Meyer_Olkin (KMO) test and Bartlett's sphericity test the KMO and Bartlett test are two statistical procedures that measure the quality of the correlation between variables. The KMO is a statistic test that varies between 0 and 1 and compares the zero-order correlations with the partial correlations observed between the variables.

3. Internal consistency Cronbach's alpha - Cronbach's Alpha is commonly used to measure internal consistency of a group of variables (items). It can be defined as the correlation that is expected between the scale and other scales using the same hypothetical universe with an equal number of items that measure the same characteristic.

4. Cluster analysis is also a technique of exploratory multivariate analysis that groups variables into homogeneous groups or more common characteristics. Each observation belonging to a particular cluster is similar to all others belonging to that cluster, and is different from the observations belonging to other clusters. The analysis of the survey was directed to the most relevant items of the questionnaire. In what concerns QMS certification, for example, there were 19 items and correspond to the items that integrate Table 3-6.

The principal component analysis to data was applied with the help of SPSS, which allows an investigation of the multivariate structure, and provides a better interpretation of the data. The internal consistency of the subject is given by Cronbach's Alpha index, which was 0.901. It was applied to the 19 selected variables,

Table 2

Total variance (Mendes, 2007).

\begin{tabular}{|c|c|c|c|c|c|c|}
\hline \multirow[t]{2}{*}{ Components } & \multicolumn{3}{|c|}{ Extraction } & \multicolumn{3}{|c|}{ Rotation } \\
\hline & Total & $\%$ Variance & \% Cumulative & Total & \% Variance & \% Cumulative \\
\hline 1 & 6961 & 36,639 & 36,639 & 3117 & 16,404 & 16,404 \\
\hline 2 & 2352 & 12,380 & 49,019 & 3109 & 16,361 & 32,766 \\
\hline 3 & 1623 & 8544 & 57,563 & 2737 & 14,404 & 47,170 \\
\hline 4 & 1354 & 7124 & 64,688 & 2362 & 12,432 & 59,602 \\
\hline 5 & 1108 & 5832 & 70,520 & 2074 & 10,918 & 70,520 \\
\hline
\end{tabular}

Table 3

Aspects of the company management where QMS had the greatest impact/benefit (Mendes, 2007).

\begin{tabular}{|c|c|c|c|c|}
\hline & $\begin{array}{l}\text { Major } \\
\text { Impact }\end{array}$ & Impac & $\begin{array}{l}\text { Little } \\
\text { Impact }\end{array}$ & $\begin{array}{l}\text { No } \\
\text { Impact }\end{array}$ \\
\hline Internal Organization of the company & $72 \%$ & $22 \%$ & $6 \%$ & $0 \%$ \\
\hline $\begin{array}{l}\text { Continuous assessment through } \\
\text { internal audits }\end{array}$ & $54 \%$ & $44 \%$ & $2 \%$ & $0 \%$ \\
\hline Enterprise image & $52 \%$ & $46 \%$ & $2 \%$ & $0 \%$ \\
\hline Ease of access to information & $44 \%$ & $39 \%$ & $15 \%$ & $2 \%$ \\
\hline
\end{tabular}

considering 5 analysis components. As this value was greater than 0.7 , the responses were considered as trustworthy and free of errors (Mendes, 2007).

Within this context, we used score 4 for "Greater Impact", 3 for "Impact", 2 for "Little Impact" and 1 for "No impact". For the principal component analysis, the sufficient number to explain the total set of variables is 5 parts, as they explain more than $70.5 \%$ of the total variance, as shown in Table 2 . The scree plot (graph of the number of variance components, where the maximum gradient points are indicative of the appropriate number of components to retain) shows a trend parallel to the horizontal line from the component 5, as shown in Fig. 3; this allowed us to conclude that five main components was a satisfactory number to be used.

\section{Results}

Not so long ago, some SMEs in Portugal and other countries, although a small percentage, began to certify their management systems. The first system that was certified was the Quality Management System (QMS). When this system was consolidated, the Environmental Management System (EMS) was then certified. Only after this system was consolidated did companies certify the Safety Management System (SMS), which started quite recently. After the three certifications, firms started to develop integrated procedures to integrate two systems (quality and environment or safety) in a staggered way, and whenever possible, the three systems (quality, environment and safety) (Santos et al., 2008; Santos and Lima, 2004).

This has been, more or less, the general rule that Portuguese SMEs have adopted, confirmed by the number of certifications, where the quality stands out in the first place (QMS), followed by environmental certification (EMS) and finally the safety certification (OHSMS).

However, we know that some SMEs have adopted another rule in sporadic cases. After the certification of quality according to ISO 9001, common procedures have been designed for the Environmental Management System (EMS) and the Occupational Health and Safety Management System (OHSMS) at work certification, which worked as the embryo for the implementation of a set of Integrated Management procedures.

\subsection{The main benefits that companies have gained from QMS certification}

Certification is certainly a strategic option for developing organizations in the sense of a wiliness to improve and gain market

Table 4

How companies classify the impact of QMS in the increase in the number of customers (Mendes, 2007).

\begin{tabular}{|c|c|c|c|}
\hline & $\begin{array}{l}\text { Major } \\
\text { Impact }\end{array}$ & $\begin{array}{l}\text { Impact Little } \\
\text { Impact }\end{array}$ & $\begin{array}{l}\text { No } \\
\text { Impact }\end{array}$ \\
\hline $\begin{array}{l}\text { Increase in the number of } \\
\text { customers }\end{array}$ & $20 \%$ & $37 \%$ & $6 \%$ \\
\hline
\end{tabular}


Table 5

How companies classify the impact of QMS in other aspects of their activity (Mendes, 2007).

\begin{tabular}{|c|c|c|c|c|}
\hline & $\begin{array}{l}\text { Major } \\
\text { Impact }\end{array}$ & Impact & $\begin{array}{l}\text { Little } \\
\text { impact }\end{array}$ & $\begin{array}{l}\text { No } \\
\text { Impact }\end{array}$ \\
\hline Company Productivity & $11 \%$ & $57 \%$ & $26 \%$ & $6 \%$ \\
\hline Competitive Position & $30 \%$ & $50 \%$ & $16 \%$ & $4 \%$ \\
\hline Deadlines & $9 \%$ & $50 \%$ & $32 \%$ & $9 \%$ \\
\hline External customer satisfaction & $28 \%$ & $48 \%$ & $17 \%$ & $7 \%$ \\
\hline Employee satisfaction & $17 \%$ & $48 \%$ & $28 \%$ & $7 \%$ \\
\hline $\begin{array}{l}\text { Number of external complaints } \\
\text { reduction }\end{array}$ & $20 \%$ & $47 \%$ & $31 \%$ & $2 \%$ \\
\hline Number of internal defects/scrap & $22 \%$ & $45 \%$ & $22 \%$ & $11 \%$ \\
\hline Profitability of the company & $15 \%$ & $44 \%$ & $30 \%$ & $11 \%$ \\
\hline $\begin{array}{l}\text { Involvement of all in solving the } \\
\text { problems of quality }\end{array}$ & $39 \%$ & $43 \%$ & $18 \%$ & $0 \%$ \\
\hline Performance (cost savings) & $15 \%$ & $43 \%$ & $35 \%$ & $7 \%$ \\
\hline Achievement of some important client & $17 \%$ & $35 \%$ & $31 \%$ & $17 \%$ \\
\hline Volume of deliveries & $7 \%$ & $33 \%$ & $30 \%$ & $30 \%$ \\
\hline
\end{tabular}

share. With the reality of the growing number of certified companies, it is important to analyze and quantify the benefits that companies have gained from the certification of their quality system.

Considering the descriptive analysis of responses and the analysis of each item separately, it can be concluded that certification of Quality Management System led companies to improve their internal organization, to improve the access to information and the internal evaluation of the management systems (namely through continuous audits in time); it also had a beneficial effect on the company's image, as depicted in Table 3.

It is clear from Table 3 that these were, in fact, the major benefits of QMS certification. 72\% of the companies referred that the major achievement was in their internal organization, and only $6 \%$ referred that certification had little impact on this particular aspect. $52 \%$ of the companies stated that their image was improved as a consequence of certification. The basis for these statements was the increase in the number of new or potentially new customers, the drastic reduction of customers' rejections and the increase of customers satisfaction (evaluated not only by the decrease in the number of rejections, but also by the increase in the sales volume for those same customers and the increased satisfaction with the overall quality of the products).

Moreover, no company reported having felt some sort of impact in any aspect of their management structure, as inferred by the results presented in column "no impact" of Table 3.

Only a few companies (20\%) stated that QMS certification had a major influence on the increase of the number of customers. Thus, this aspect was not considered as the most relevant benefit for most of them. Nevertheless, 37\% of them stated that QMS had increased the number of customers, thus they consider QMS had an important positive impact in the number of their customers, while $37 \%$ referred that QMS had a small positive impact on that parameter. Since an increase in their number of customers occurred but it was not so high as it could be expected, as presented in Table 4 .

In general, companies with the certified QMS managed to achieve higher efficiency indicators, as shown in Table 5. Aspects like company productivity, competitiveness, accomplishment of delivery

\section{Table 6}

How companies classify the impact of QMS in absenteeism and product innovation (Mendes, 2007).

\begin{tabular}{lllll}
\hline & Major Impact & Impact & Little Impact & No Impact \\
\hline Absenteeism & $2 \%$ & $17 \%$ & $37 \%$ & $44 \%$ \\
Product innovation & $15 \%$ & $22 \%$ & $30 \%$ & $33 \%$ \\
\hline
\end{tabular}

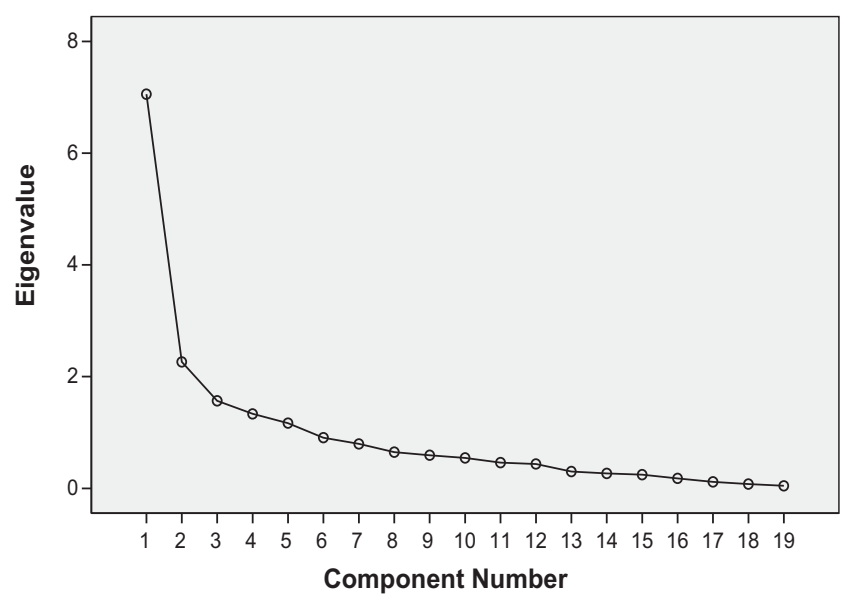

Fig. 3. Scree Plot Graph of the survey question related to the main benefits of certification, resumed in Table 3-6.

times, increase in both customers and employee satisfaction, reduction of customer's complaints and internal rejections were considered aspects where QMS certification had a relevant, but not a major impact or benefit. Nevertheless its importance is clearly identified by the companies, evaluated by the increase in profitability, volume of deliveries, number of new "important" customers and cost savings. Among all those aspects, company's productivity, competitiveness and accomplishment of delivery times can be considered the most relevant aspects where QMS had a significant impact, since they were highlighted by more than $50 \%$ of the companies, as presented in Table 5.

In general, companies have found that QMS certification did not lead to a reduction in absenteeism. $44 \%$ mentioned that no impact at all was felt in this particular aspect, and $37 \%$ mentioned little impact (evaluated by a reduction in the number of hours of absenteeism/year), as presented in Table 6 .

In what concerns to product innovation, a similar situation occurred. 37\% of the companies referred that QMS certification had a moderate or major impact on the development of new products and innovation, while $63 \%$ pointed out that only a small, or even no impact was registered (Table 6). This is quite uncommon, but can be explained taking into account the profile of the Portuguese industrial sector, which is based on companies that are subcontracted and the low number of enterprises with product development activities. Thus, according to the survey, the contribution of the QMS certification to innovation has not been very significant.

\subsection{The main benefits that companies have gained with EMS and OHSMS certification}

The three standards of ISO 9001, ISO 14001 and OHSAS 18001 have a common underlying principle: continuous improvement based on Deming's Cycle (Plan-do-Check-Act) (Zeng et al., 2007). Table 7 deals with the Deming's Cycle of continual improvement approach, adapted to our study from the Deming's Cycle suggested by Badreddine et al. (2009). According to Labodová (2004), basically one PDCA approach governing the aspects of quality, environment and safety, consistent with clear priorities, shows hot spots in companies, makes it easy to focus procedures and responsibilities on important areas.

According to the survey, all companies in the sample had their QMS certified. 26.1\% of these companies also had their EMS certified, and only $15.2 \%$ had OHSMS certification. In Table 8 , a summary of the main benefits, classified according to their impact relevance, 
Table 7

Deming's Cycle of continual improvement approach.

\begin{tabular}{|c|c|c|c|c|}
\hline $\begin{array}{l}\text { Standards } \\
\text { Deming's } \\
\text { Cycle } 』\end{array}$ & ISO 9001:2008 & ISO 14001:2004 & $\begin{array}{l}\text { OHSAS } \\
\text { 18001:2007 }\end{array}$ & IMS (next step) \\
\hline PLAN & $\begin{array}{l}\text { Quality } \\
\text { objectives } \\
\text { planning }\end{array}$ & $\begin{array}{l}\text { Environmental } \\
\text { objectives } \\
\text { planning }\end{array}$ & $\begin{array}{l}\text { Safety and health } \\
\text { objectives } \\
\text { planning }\end{array}$ & $\begin{array}{l}\text { Integrated } \\
\text { objectives } \\
\text { planning }\end{array}$ \\
\hline DO & $\begin{array}{l}\text { Product } \\
\text { Manufacturing }\end{array}$ & $\begin{array}{l}\text { Implementation } \\
\text { of } \\
\text { environmental } \\
\text { program }\end{array}$ & $\begin{array}{l}\text { Implementation } \\
\text { of safety and } \\
\text { health program }\end{array}$ & $\begin{array}{l}\text { Functioning of } \\
\text { integrated } \\
\text { program }\end{array}$ \\
\hline CHECK & $\begin{array}{l}\text { Checking and } \\
\text { analysis of } \\
\text { product defects }\end{array}$ & $\begin{array}{l}\text { Checking and } \\
\text { analyses of } \\
\text { environmental } \\
\text { impacts }\end{array}$ & $\begin{array}{l}\text { Checking and } \\
\text { analyses of the } \\
\text { main drawbacks } \\
\text { and difficulties }\end{array}$ & $\begin{array}{l}\text { Checking the } \\
\text { integrated } \\
\text { items/program }\end{array}$ \\
\hline ACT & $\begin{array}{l}\text { Proposals of } \\
\text { improvements/ } \\
\text { management } \\
\text { review }\end{array}$ & $\begin{array}{l}\text { Proposals of } \\
\text { improvements/ } \\
\text { management } \\
\text { review }\end{array}$ & $\begin{array}{l}\text { Proposals of } \\
\text { improvements/ } \\
\text { management } \\
\text { review }\end{array}$ & $\begin{array}{l}\text { Proposals of } \\
\text { improvements/ } \\
\text { management } \\
\text { review }\end{array}$ \\
\hline
\end{tabular}

as well as the main reasons for the three certification systems, is presented. Moreover, the main factors that justify the option for non-certification of EMS and OHSMS of the remaining companies are also presented. The main factors that justify the option for noncertification of QMS are not presented, since every company participating in the survey had their QMS certified.

In what concerns EMS certification, the main reasons referred for certification have been environment protection, improvement of the company's image in this field, improvement quality of life inside and in the surroundings of the enterprise and the marketing strategy, with particular relevance for the first three. The main benefits of EMS certification were classified as having major, relevant and low or any impact in several fields. Those fields where a major impact of certification had been detected were environment protection (evaluated by the decrease in the amount of residues and disposal costs), better integration of the company in the community, rationalization of natural resources, implementation of recycling techniques (and consequent decrease of costs related to

\section{Table 8}

Summary of the benefits and impact grade characterization that companies obtained with certification of the management systems.

\begin{tabular}{|c|c|c|c|c|}
\hline \multirow[t]{15}{*}{ Q M S } & \multicolumn{4}{|l|}{$100 \%$ are certified by ISO 9001} \\
\hline & \multirow[t]{3}{*}{ Reasons for certification } & Very Important & Empowering workers knowledge & Business benefits \\
\hline & & & Better quality of the products & Improvement of company image \\
\hline & & Important & Customers pressure & Community relations \\
\hline & \multirow[t]{6}{*}{ Benefits } & Major Impact & Enterprise image & Ease of access to information \\
\hline & & & Internal organization of the company & Continuous assessment through internal audits \\
\hline & & Impact & Productivity and profitability & Deadlines \\
\hline & & & Cost reduction & Number of defects/complaints \\
\hline & & & Competitive position & Satisfaction of internal and external customers. \\
\hline & & Little Impact & Absenteeism & Product innovation \\
\hline & \multirow[t]{3}{*}{ Tools } & Most commonly used & Surveys & Charts (graphics) \\
\hline & & & Sheets of data collection & \\
\hline & & Less used & Scatter diagram & Cause and effect diagram \\
\hline & \multirow{2}{*}{\multicolumn{2}{|c|}{ Difficulties }} & High certification costs & Difficulties to change company's culture \\
\hline & & & Difficulties to motivate personal & \\
\hline \multirow[t]{16}{*}{ E M S } & \multicolumn{4}{|l|}{$26.1 \%$ are certified by ISO 14001} \\
\hline & \multirow[t]{3}{*}{ Reasons for non-certification } & Main reason & Lack of investment support & A form of marketing \\
\hline & & Secondary reason & Benefits do not outweigh the costs & Investments are high \\
\hline & & Less Relevant & Environmental risks are low & \\
\hline & \multirow[t]{2}{*}{ Reasons for certification } & Very Important & $\begin{array}{l}\text { Progress but always protect the } \\
\text { environment } \\
\text { Improved quality of life inside and } \\
\text { outside the company }\end{array}$ & Raising public \\
\hline & & Important & \multicolumn{2}{|l|}{ Obtaining an asset in terms of marketing } \\
\hline & \multirow[t]{7}{*}{ Benefits } & Major Impact & Environmental protection & Rational use of natural resources \\
\hline & & & Business image in the community & Recycling \\
\hline & & & Ensuring compliance & Prevention of environmental risks \\
\hline & & Impact & Clear, organized work environment & Waste generation \\
\hline & & & Awareness of employees in environmen & ntal issues \\
\hline & & No impact & Insurance costs & Costs of raw-materials and equipment \\
\hline & & & $\begin{array}{l}\text { Ability to obtain financing at } \\
\text { low interest rates }\end{array}$ & \\
\hline & \multicolumn{2}{|l|}{ Drawbacks } & \multicolumn{2}{|c|}{ Overall costs increased on the early stages of certification. } \\
\hline & \multirow{2}{*}{\multicolumn{2}{|c|}{ Main Difficulties }} & High certification costs & Difficulties to change Company's culture \\
\hline & & & Difficulties to motivate personal & \\
\hline \multirow[t]{15}{*}{ O H S M S } & \multicolumn{4}{|l|}{$15.2 \%$ are certified by OHSAS 18001} \\
\hline & \multirow{3}{*}{ Reasons for non-certification } & Main reason & Investments are high & Certification is seen as a cost and marketing \\
\hline & & Secondary reason & Benefits do not outweigh the costs & \\
\hline & & Less Relevant & Risk of accidents at work are low & \\
\hline & \multirow[t]{3}{*}{ Reasons for certification } & Very important & Eliminate or minimize risks to workers & \\
\hline & & Important & Improving the organization with the red & duction of accidents at work \\
\hline & & Less Important & Rate of absenteeism due to occupationa & al diseases \\
\hline & \multirow[t]{4}{*}{ Benefits } & Major Impact & Improvement of working conditions & Better internal communication \\
\hline & & & Improvement company image. & Ensuring compliance with legislation \\
\hline & & Impact & Less number of accidents & Reduction in cost of accidents and occupational diseases \\
\hline & & No impact & Dissemination in the media of data on $\mathrm{s}$ & safety and health of the company \\
\hline & Drawbacks & & No drawbacks have been referred & \\
\hline & \multirow{3}{*}{ Main Difficulties } & & High certification costs & Difficulties to change Company's culture \\
\hline & & & Difficulties to motivate personal & Increase bureaucracy \\
\hline & & & Management difficulties in the early sta & ages of certification \\
\hline
\end{tabular}


raw-materials acquisition), legislation compliance and consequent decrease of penalty costs. Those companies with non-certified EMS highlighted the lack of investment support, high implementation costs when compared with the foreseen benefits of certification, or irrelevant environmental risks associated to their activity as the main reasons for their non-certification decision.

Regarding OHSMS certification, the main reason mentioned for certification dealt with the objective of reducing labor accidents by minimizing accident risks. Moreover, although not so important, there has been environment protection and improvement of the company's image, by reducing accidents and decreasing absenteeism due to labor accidents or diseases. The main benefits identified from OHSMS certification have been the improvement of working conditions, the decrease in the number of accidents and their associated costs, which helped to improve the company's image in the surrounding area and among customers, as well as the increase in profitability Those companies with non-certified OHSMS mentioned high implementation and maintenance costs, considering the benefits arising from certification, and because they considered OHSMS certification as an image issue only concerned with marketing purposes and having no practical effects in the company's daily activity itself. Moreover, some of the companies did not consider their activity as dangerous, so gains from certification would have been reduced.

3.3. The main benefits and drawbacks that companies have gained with the integration of quality, environment and safety systems

Quality, environment and safety certification have a large impact on companies, at the internal, external and operational levels. The certification of these Management Systems includes many common procedures that can be an integrated basis, as illustrated in Fig. 4.

The synergy that an Integrated Management System (IMS) can offer have driven organizations into higher levels of performance at a cost lower than that associated to independent certification management systems. The simple schematic in Fig. 4 represents the vision of an IMS-QES, suggesting that they have common information and procedures.

Integration can be achieved at different levels, leading to partially or fully integrated systems. A partially integrated system keeps their manuals separated using integrated procedures. A fully integrated system is based on a single manual that integrates unified management systems requirements.

In Portugal, integration of management systems is quite recent and the number of Small and Medium Enterprises (SMEs) with some sort of integrated systems is very low, since integration costs are very high. Moreover, only a few companies have an OHSMS

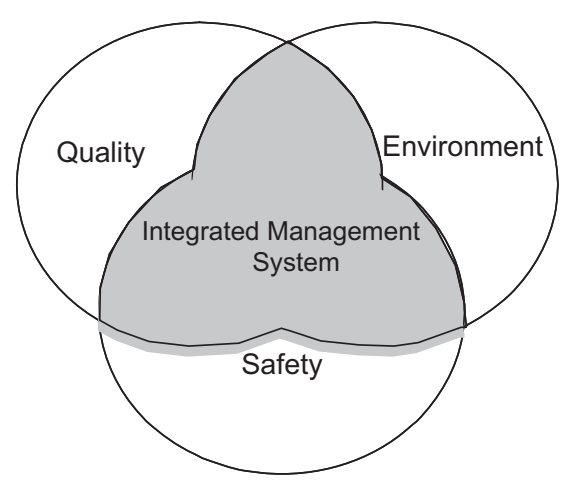

Fig. 4. Schematic representation of an Integrated Management System. implemented and, among them, only a small percentage has a certified system. On the other hand, a large number of companies have a certified OHSMS system but they are not quality or environmentally certified, like many building companies.

Integration of Quality, Environment and Safety Management Systems are known to have potential benefits over the companies' efficiency. Moreover, integrating IMS-QES enhances organizational performance. Thus, in a team, all employees contribute to the mission and to the defense of the values of a unique organization, improving the overall development of the company, thus improving the image of the organization. However, an unsuitable integration process can bring additional problems, like increased strictness, inefficiency and even professional and cultural conflicts. Thus, a careful reflexion about the way to start and run an integration process is crucial.

According to the survey, only $15.2 \%$ of the companies have the three systems certified, which corresponds to 7 companies of our sample, and all of them are running partially integrated management systems. As the size of the sample was very small (although it corresponds to the Portuguese reality), a thorough statistical analysis of the answers to the survey questions was not carried out, and only benefits, drawbacks, difficulties concerning the integration process and level of integration are presented. Table 9 presents the main results of that analysis.

In what concerns the level of integration, no company had fully integrated their management systems, as referred above. However, all of them have achieved some level of integration, with particular emphasis to internal audits, control documents, non-conformities, registries, corrective and preventive actions, management responsibilities, employee training and some procedures (ex: resources management; product realization; evaluation of results for improvement). Nevertheless, all of them kept independent systems

Table 9

Main benefits, drawbacks and difficulties of IMS implementation in Portuguese SMEs.

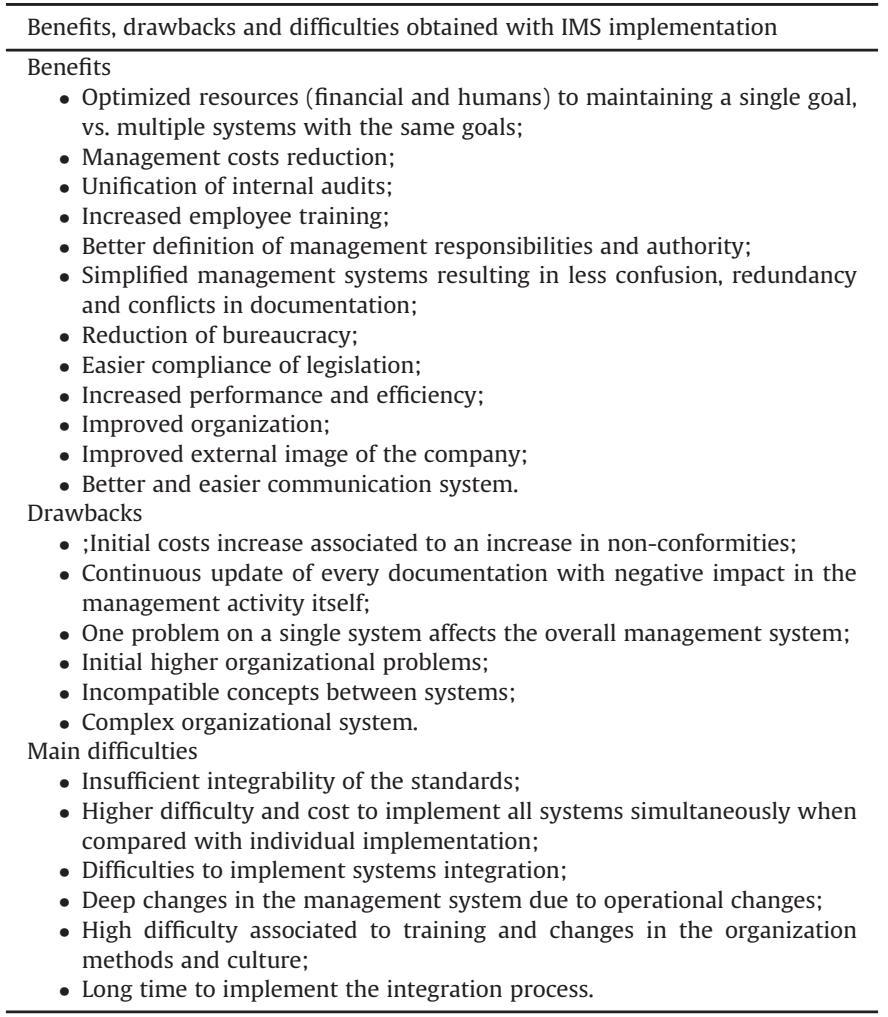


manuals and some management procedures. In Table 10 the most frequent integrated items of the management systems in the companies that answered the survey are presented.

Regarding the last question of the survey - "Would the company prefer one single standard for the certification of every management system?" $75 \%$ of the companies responded affirmatively to this question, justifying their answer with general aspects concerned with cost reduction and easier management control. The companies that preferred separate standards based their answer on the individual implementation of the referred systems, since integration requires deep changes in the management system due to operational changes. On the other hand, one problem in a single system would affect the overall management system.

\section{Discussion}

The management system team can control the structure of each subsystem by using the administrative controls established in the quality subsystem for other management subsystems, such as responsible care, process safety, health and safety, environment, materials transportation, etc. (Holdsworth, 2003). According to Pascal (1997) quality, environment and health and safety, are three of industry's most pressing concerns. The standards for quality management (ISO 9001), environment management (ISO 14001) and health and safety management (OHSAS 18001) contain the same basic disciplines, and a general common structure that can be integrated quite easily. Thus, in accordance with Pojasek (2006), one of the first major international standards to come on the scene was ISO 9001. It was followed by ISO 14001. Our research confirms the idea that a high percentage of organizations with an EMS, in accordance with the ISO 14001, had also implemented, a certified QMS, in accordance with ISO 9001. This is also in line with reports from Karapetrovic and Casadesús (2009); McDonald et al. (2003); Arifin et al. (2009); Casadesús et al. (2008).

In what concerns environment, a good example is reported by Fresner et al. (2007) in Austria, where the approach of the Zero emission retrofitting method for existing galvanizing plants (ZERMEG) was supported by the Austrian Ministry for Science and Technology within the programme "Factory of the future". This concept and programme is very interesting and unfortunately does not exist in many countries, Portugal included.

In relation to health and safety in the workplaces, our research is in line with the study done by Tsai and Chou (2009), where creating and maintaining a safe working environment assures workers high health levels, protecting them from accidents, illness or discomfort in the workplace, and increases the efficiency of work processes, improves employee perceptions of the working environment and leads to high recruitment attractiveness.

Concerning the level of integration, the findings of our research are in line with McDonald et al. (2003), who suggest that an integrated system processes may include, among others: management

Table 10

Main integrated items in the Portuguese QMS, EMS and OHSMS certified companies.

\begin{tabular}{ll}
\hline What was integrated? & $\begin{array}{l}\text { Number of } \\
\text { companies }\end{array}$ \\
\hline Internal audits & 7 \\
Documents control & 7 \\
Employee training & 7 \\
Registries & 7 \\
Management responsibilities & 6 \\
Corrective and preventive actions & 5 \\
Non-conformities & 4 \\
Some procedures (ex: resources management; product & 4 \\
$\quad$ realization; evaluation of results for improvement) & \\
\hline
\end{tabular}

responsibilities; definition and communication of the policy statement; definition and communication of objectives, targets and goals; definition of responsibilities and authorities; provision of adequate recourses; control of documents; employee training; definition and review of customer requirements; control of design and development; identification of environmental aspects and impacts; hazard identification and risk analysis; internal audits; control of nonconforming product; measurement of customer satisfaction; corrective and preventive actions. Thus, integration is not a mountain to climb: it is in fact far easier than trying to install a stand-alone system. In short, it makes good sense to put the three (or two) into one, as stated by Wright (2000).

The findings of this research is in line with that of other authors, like Jørgensen et al. (2006), in the "corresponding" level of integration, since an increase of compatibility with cross-references between parallel systems was verified. The same result was found by Arifin et al. (2009), who reported on the integration of the document system in Malaysian companies, and Labodová (2004), who reported on the integration of originally separated systems in Czech Republic companies.

Our study is also in accordance with Duijm et al. (2008), who carried out a study in several EU countries (Denmark, Greece, France, Slovenia, Poland, Belgium and Germany) and verified that in small companies integration takes place naturally, and a single person is responsible for its management, often covering concurrent tasks, which can make it difficult to identify priorities; this is similar to what happens in Portugal. Moreover, although most Portuguese companies also consider that HSE systems contribute to increase profitability and to protect the environment, we consider that the situation in Portugal and other countries is similar, like in Lithuania for example, as reported by Staniskis and Stasiskiene (2006), who consider that HSE systems implementation is still driven by economic benefits rather than by "green idealism".

In others studies, like Bernardo et al. (2009) on Spanish Companies, a very large number of enterprises $(87 \%$ of 362 companies) have a great part of their Management Systems already integrated. Portugal has a long way to go, but it is determined to stand alongside the best. Another study by the same researchers (Bernardo et al., 2010) revealed that internal and external audits are integrated to some degree or for some components or aspects, regardless of whether or not the implemented Management Systems are themselves integrated. This is in line with our study and this pattern is in line with the findings of other researchers, such as Karapetrovic and Casadesús (2009), confirming that organizations prefer integration of management system audits to managing and conducting them separately.

Concerning the main benefits arising from IMS implementation, our study is in accordance with Salomone (2008) reports concerning IMS implementation in Italian companies, who reported the reduction of documentation, human resources optimization, time savings, less bureaucracy, optimization of internal audit, among other things. Our study detected difficulties associated with IMS implementation, reported by the same author, namely the difficulty of the implementation process itself and insufficient integrability of the individual standards. The benefits of integration referred by the Portuguese SMEs have also been suggested by McDonald et al. (2003), namely, simplified systems resulting in less confusion, redundancy or conflicts in documentation; optimized resources in maintaining a single goal vs. multiple systems with the same goals, and also by Bobrek and Sokovic (2006) namely, internal management methods and cross-functional teamwork, fewer multiple audits and reduced costs. Our study is also in accordance with Wright (2000) who reported that combining all three Management Systems to implement a single Integrated Management System (IMS) can promote significant cost reduction (in 
external audits, for example). Among others aspects, in what concerns cost reduction and processes simplification, our study is also in accordance with Asif et al. (2010) reports related to IMS in Pakistani companies.

To conclude, the authors of this work agree with Pascal (1997) when he reported that the economy of the twenty-first century will place a premium on the broadly skilled, flexible generalist, who is able to view a problem from many angles at once and who has many arrows in the quiver.

\section{Conclusions}

Several relevant conclusions can be drawn from this research. In first place, it confirms that the first management system to be implemented by Portuguese firms was the QMS, followed by the EMS and much later, in third place, the OHSMS.

In what concerns quality, the main benefits that companies gained with QMS certification were: major achievement in their internal organization (72\%), continuous assessment though internal audits (54\%), improvement of their image (52\%) and ease in the access of information (44\%). Few companies (20\%) referred that QMS certification had a major influence on the number of increased customer, but $37 \%$ of them revealed that QMS certification had an important positive impact in the increase of the number of their customers. There are other secondary aspects that companies gained with QMS certification such as: increase of productivity (57\%), employee satisfaction (48\%) and external customer satisfaction (48\%). There are also other aspects considered by the companies as less relevant, although also important, such as performance - cost savings (43\%) and volume of deliveries (33\%). In what concerns product innovation, $37 \%$ of the companies referred that QMS certification had a moderate impact on their structure and performance and $44 \%$ mentioned that they felt no impact at all.

The main reasons that led companies to the implementation of the EMS were environment protection, advance in quality of life inside and outside the company and the improvement of the company's public image. Hence, companies are becoming mindful about the importance of environmental issues. The major EMS impact referred by the SMEs resulted in environmental protection, the improvement of the company's image in the community, ensuring compliance and recycling, rational use of natural resources and recycling and prevention of environmental risks. There are, however, secondary aspects, such as clear and organized work environment, awareness of employees in environmental issues and generation of less waste.

The main reasons for SMEs to seek OHSMS certification were, among others, to eliminate or minimize risks to workers, improve the image of the company by reducing the number of labor accidents and in third place, but also important, reduce the rate of absenteeism due to occupational diseases. The major impacts of OHSMS certification on SMEs were the improvement of the conditions in the workplace, ensuring compliance with health and safety legislation, a more effective communication about risks and dangers to employees, which strengthened the image of the organization. SMEs have also referred the decrease in the number of accidents and occupational diseases and their respective costs reduction.

Through the literature review and the statistical analysis of surveys, we concluded that there are still very few Portuguese SMEs with all three management systems implemented and certified. The number of SMEs with QMS and EMS certification is already considerable but their implementation is recent. Concerning OHSMS certification, its implementation is still very low. Hence, integration of the three management systems in Portuguese SMEs is also very low. Moreover, after the completion of the statistical survey, it appears that the partial integration of the referred Management Systems of SMEs has advantages in terms of optimized resources (financial and humans) to maintaining a single goal vs. multiple systems with the same goals; reduction of management costs, unification of internal audits, increased employee training, better definition of management responsibilities and authority, simplified management systems resulting in less confusion, redundancy and conflicts in documentation, easier compliance of legislation, improved organization and improved external image of the company. Simultaneously, some drawbacks were identified, such as increased initial costs associated with a raise in non-conformities, need to continuously update all documentation, with a negative impact in the management activity itself, incompatible concepts between systems and certainly, the fact that one problem in a single system may affect the overall management system. Some difficulties to implement integration policies were referred too, such as insufficient integrability of the standards, higher difficulty and cost to implement all systems simultaneously when compared with individual implementation and deep changes in the management system due to operational changes, which led to a high difficulty associated to training and changes in the organization methods and company culture.

We feel that the integration and unification of the three management systems will be the future of management systems. We believe that the compatibility among different standards for the effective integration of the different systems should be done in moderation. For this to happen, it is very important to ensure that there is not a strong/rich group of companies leading a large platoon of companies with greater difficulties to implement/ manage the integration of their management systems.

\section{Acknowledgments}

We would like to thank the Portuguese SMEs that participated in this research and that kindly answered the questionnaires.

\section{References}

Arifin, K., Aiyub, K., Awang, A., Jahi, J.M., Iten, R., 2009. Implementation of integrated management system in Malaysia: the level of Organization's understanding and awareness. European Journal of Scientific Research. ISSN: 1450-216X 31 (2). ISSN: 1450-216X, 188-195.

Asif, M., Fisscher, O.A.M., Bruijn, E.J., Pagell, M., 2010. Integration of management systems: a methodology for operational excellence and strategic flexibility. Operations Management Research 3, 146-160.

Badreddine, A., Romdhane, T.B., Amor, N.B., 2009. A New Process-Based Approach for Implementing an Integrated Management System: Quality, Security, Environment. In: Proceedings of the International Multi Conference of Engineers and Computer Scientists, vol. II. IMECS, Hong Kong.

Bernardo, M., Casadesus, M., Karapetrovic, S., Heras, I., 2009. How integrated are environmental, quality and other standardized management systems? An empirical study. Journal of Cleaner Production 17, 742-750.

Bernardo, M., Casadesus, M., Karapetrovic, S., Heras, I., 2010. An empirical study on the integration of management system audits. Journal of Cleaner Production 18, 486-495.

Block, M.R., Marash, I.R., 2002. Integrating ISO 14001 into a Quality Management System, second ed. ASQ Milwaukee.

Bobrek, M., Sokovic, M., 2006. Integration concept and synergetic effect in modern management. Journal of Materials Processing Technology 175, 33-39.

Burke, S., Gaughran, W.F., 2007. Developing a framework for sustainability management in engineering SMEs. Robotics and Computer-Integrated Manufacturing 23, 696-703.

Casadesús, M., Marimon, F., Heras, I., 2008. ISO 14001 diffusion after the success of the ISO 9001 model. Journal of Cleaner Production 16, 1741-1754.

Duijm, N.J., Fiévez, C., Gerbec, M., Hauptmanns, H., Konstandinidou, M., 2008. Management of health, safety and environment in process industry. Safety Science 46, 908-920.

Fresner, J., Engelhardt, G., 2004. Experiences with integrated management systems for two small companies in Austria. Journal of Cleaner Production 12, 623-631.

Fresner, J., Schnitzer, H., Gwehenberger, G., Planasch, M., Brunner, C., Taferner, K., Mair, J., 2007. Practical experiences with the implementation of the concept of zero emissions in the surface treatment industry in Austria. Journal of Cleaner Production 15, 1228-1239. 
Holdsworth, R., 2003. Practical applications approach to design, development and implementation of an integrated management system. Journal of Hazardous Materials 104, 193-205.

Jørgensen, T.H., Remmen, A., Mellado, M.D., 2006. Integrated management systems three different levels of integration. Journal of Cleaner Production 14, 713-722.

Karapetrovic, S., Casadesús, M., 2009. Implementing environmental with other standardized management systems: scope, sequence, time and integration. Journal of Cleaner Production 17, 533-540.

Labodová, A., 2004. Implementing integrated management systems using a risk analysis based approach. Journal of Cleaner Production 12, 571-580.

McDonald, M., Mors, T.A., Phillips, A., 2003, October. Management system integration: can it be done? Quality Progress, 67-74.

Mendes, F., 2007. O Impacto dos sistemas QAS nas PMEs portuguesas - Master Thesis - Univ. Minho.

Pojasek, R.B., 2006. Is Your Integrated Management System Really Integrated? Environmental Quality Management Wiley Periodicals, Inc. Published Online in Wiley Inter Science, winter pp. 89-97.

Pascal, D., 1997. Quality, Safety and Environment - Synergy in the 21st Century. ASQ Milwaukee.

Salomone, R., 2008. Integrated management systems: experiences in Italian organizations. Journal of Cleaner Production 16, 1786-1806.
Santos, Gilberto, et al., 2008. Implementação de Sistemas Integrados de Gestão (Qualidade, Ambiente e Segurança). Publindústria, ISBN 978-972-8953-26-3.

Santos, M.G., Lima, F., 2004. Integração de sistemas de gestão - a situação em Portugal, in: V Congreso Galego da Calidade, Santiago de Compostela; Maio.

Santos M.G., Barbosa J., Pedro C., Integration of "QES" Systems on the Small and Medium Size Foundry Companies in Portugal. Communication Presented at the 66th Would Foundry Congress. 6-9 September 2004; Istanbul, Turkey.

Staniskis, J.K., Stasiskiene, Z., 2006. Environmental management accounting in Lithuania: exploratory study of current practices, opportunities and strategic intents. Journal of Cleaner Production 14, 1252-1261.

Tsai, W.H., Chou, W.H., 2009. Selecting management systems for sustainable development in SMEs: a novel hybrid model based on DEMATEL, ANP, and ZOGP. Expert Systems with Applications 36, 1444-1458.

Wright, T., 2000. IMS-Three into one will go!: the advantages of a single integrated quality, health and safety, and environmental management system. The Quality Assurance Journal 4, 137-142.

Zeng, S.X., Jonathan, J.S., Lou, G.X., 2007. A synergetic model for implementing an integrated management system: an empirical study in China. Journal of Cleaner Production 15, 1760-1767.

Zorpas, A., 2010. Environmental management systems as sustainable tools in the way of life for the SMEs and VSMEs. Bioresource Technology 101, 1544-1557. 